\title{
40 anos a divulgar a Química em Portugal
}

O Boletim da Sociedade Portuguesa de Química, o QUÍMICA, foi criado há precisamente 40 anos. Teve como missão inicial revitalizar a Sociedade Portuguesa de Química, não só através da angariação de novos sócios, mas também para divulgação da Química que se fazia em Portugal. Neste período sofreu, naturalmente, muitas modificações. Contudo a sua essência perdurou, sendo atualmente uma publicação nacional de referência para os Químicos portugueses.

40 years communicating Chemistry in Portugal - QUíMICA, the magazine from the Portuguese Chemical Society, is celebrating 40 years of existence. Its foundation is linked to the rebuilding of the Portuguese Chemical Society, after the split of the Portuguese Chemical and Physics Society. This iconic magazine has radically changed along the years but it's true spirit survived and became a landmark for the Portuguese chemists.

O Edifício do Complexo Interdisciplinar - “o Complexo” - no Instituto Superior Técnico é um sítio muito especial. Passando a escultura mural "exaltação dos ritmos dominantes das origens” do mestre Lagoa Henriques, logo à entrada, encontramos uma atmosfera muito ao gosto dos anos 70. O colorido biombo vitral de Jorge Vieira, no átrio, a biblioteca do Arq. José Maria Segurado, as luminárias da sala de reuniões, o mobiliário, tudo parece cristalizado no tempo.

Foi neste ambiente que nasceu o Boletim da Sociedade Portuguesa de Química (SPQ). O primeiro número foi publicado em junho de 1977, há precisamente 40 anos. Para assinalar esta data especial a Direção do QUíMICA quis recolher o testemunho dos Editores que o fizeram nascer e ajudaram a crescer durante os primeiros vinte anos de existência. Sob a forma de entrevista, falámos com a Prof. ${ }^{\text {a }}$ Ana Lobo e o Prof. Virgílio Meira Soares, os primeiros Diretores, e também com o Prof. Mário Nuno Berberan e Santos, o Diretor responsável pela transição do Boletim para o QUíMICA, a edição tal como a conhecemos hoje. Recolhemos também o depoimento escrito de mais três Editores. Neste contexto, é de salientar a perspetiva histórica destes tempos embrionários, elaborada pela Prof. ${ }^{a}$ Raquel Gonçalves [1], e também alguns depoimentos recolhidos pelo Prof. Jorge Morgado, aquando da publicação do número 100 do QUímICA [2].

Agendei a entrevista com a Prof. ${ }^{a}$ Ana Lobo (Figura 1) para um fim de semana. Durante a semana a professora estava bastante ocupada pois continua a fazer investigação, tendo mesmo regressado ao laboratório! Professora catedrática de Química na FCT-UNL, jubilada em 2015, foi a primeira Diretora do Boletim da SPQ. Fui recebido na sua casa em Lisboa. Abriu-me a porta com a simpatia e vivacidade características, acompanhada da sua cadela, uma pachorrenta boxer malhada de nome Taara - que significa "estrela” em sânscrito.

Naquela época a Prof. a Ana Lobo estava a fazer investigação no Complexo, e o convite do Prof. Alberto Romão, que era então Secretário-geral da SPQ e professor no IST (sediado no Complexo), surgiu de forma natural. "O Albertinho [Prof. Alberto Romão Dias] é que me fez a proposta. Disse-me: tu é que podias tomar conta do Boletim. Mas eu não tenho experiência editorial, disse-lhe eu. Ao que ele respondeu: isso adquire-se fazendo!”.

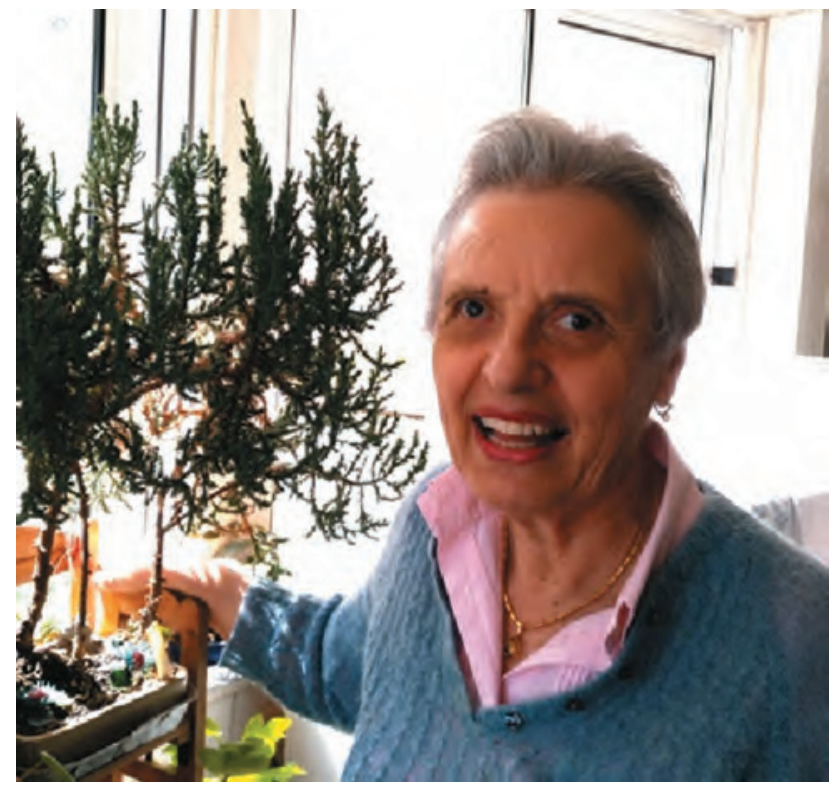

Figura 1 - Ana Lobo, primeira Diretora do Boletim da SPQ (de 1977 a 1981).

Com a criação da Sociedade Portuguesa de Física em fevereiro de 1974, a SPQ fica sucessora da antiga Sociedade Portuguesa de Química e Física. Por esta razão houve a necessidade de revitalizar a Sociedade, uma vez que nos últimos anos tinha havido uma estagnação. Publicava-se a Revista Portuguesa de Química (desde 1958), que sucedeu à Revista de Chimica Pura e Applicada (criada em 1905), mas o processo de publicação era lento e havia mesmo atrasos de vários anos nas publicações. Por outro lado, era premente divulgar a nova SPQ e angariar mais sócios. Contudo, com o 25 de abril de 1974 o processo ficou adiado e só em 1977 se concretiza esse objetivo com a criação do Boletim como plataforma para "ressuscitar a SPQ”.

O primeiro número (série I) surgiu no formato A4, mas atendendo à escassez de material, e sem uma equipa Editorial, a Prof. a Ana Lobo sentiu a necessidade de o reduzir. O segundo número saiu com um formato menor, mas “ainda estava grande”. Inspirada por outras publicações europeias, decide então fazer o terceiro número e seguintes desta série no formato B5 (metade do A4), um tamanho mais pequeno e em que se gastava menos papel (o papel 
era caro!) e menos tinta! "Foi nesta altura que o SP [Prof. S. Prabhakar, marido] me comprou a máquina da IBM" (Figura 2).
É curioso notar que numa das edições da série II surge um artigo sobre grafia Química Braille [3], um tópico muito à frente no tempo se considerarmos que até muito recen-
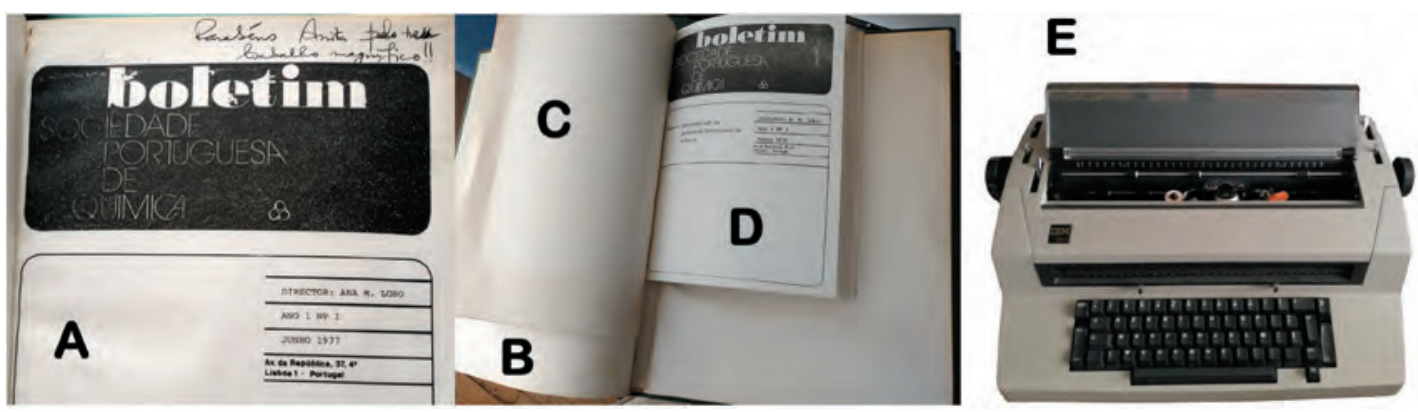

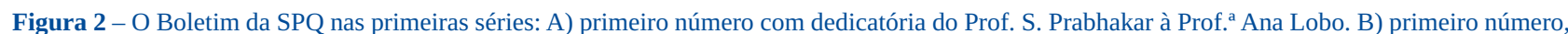
em formato A4. C) segundo número, em formato inferior a A4. D) terceiro número e seguintes da série I, em formato B5. E) máquina de escrever usada na produção do Boletim. Acervo histórico da Prof. ${ }^{a}$ Ana Lobo.

A máquina de escrever elétrica, com duas cabeças que proporcionavam dois tipos de fonte, veio facilitar muito a escrita. Não existiam computadores, o primeiro Departamento de Informática surgiu em 1977 na Universidade NOVA de Lisboa. Depois de pronta, a edição era fotocopiada pela secretária da SPQ, que também batia à máquina (de escrever) os endereços dos sócios em etiquetas, um a um, e enviava depois o Boletim por correio.

Em termos de conteúdos, havia a preocupação de informar os sócios, razão pela qual encontramos informação, por exemplo, sobre o Centro de Documentação Científica e Técnica (CDCT), com a lista das publicações periódicas acessíveis em Lisboa, a realização de cursos, congressos e conferências no estrangeiro, e até mesmo listas com os investigadores portugueses (bolseiros) a fazer investigação no estrangeiro! Esta informação era recolhida no Instituto Nacional de Investigação Científica (INIC) e podemos dizer que antecipou, na essência, a plataforma gps.pt, criada recentemente.

Existiam também minutas em inglês que os sócios podiam usar para pedir informação ao estrangeiro (newsletters, etc.). "Tinha a preocupação que os portugueses se chegassem à frente, e fossem buscar a informação onde ela existia. Em Portugal havia pouca”. Outra preocupação era a Segurança nos Laboratórios, razão pela qual cria a secção "Segurança”, coordenada por M.J.O. Baptista [Doutora Maria João Marcelo Curto].

A partir da série II, o Boletim começou a ser executado numa gráfica. Este passo foi importante, mas havia por vezes problemas pois eles nem sempre cumpriam os prazos, e textos escritos no futuro, eram já passado aquando da publicação... O Boletim passou também a ter uma capa ilustrada, da autoria da Editora, cujo arranjo final era feito depois na gráfica. O Editorial começou também a ser acompanhado por uma coluna contendo informação sobre a composição da SPQ. Nesta altura o Boletim retomou o formato A4 inicial, agora justificado pelo crescente volume de informação, e chegava aos sócios dobrado ao meio enrolado numa fita de papel.

Existia uma forte preocupação com o ensino da Química no Ensino Secundário e a formação destes professores. "Durante anos os professores do Ensino Secundário não tinham sido encorajados a aderir à SPQ porque se achava que a SPQ não era para eles”. temente [4] os invisuais não tinham qualquer ferramenta para o desenho de estruturas químicas. "A problemática dos cegos é um assunto a que fui exposta muito cedo e que me tocou muito. Os cegos ganharam asas na informação com a introdução dos computadores”, refere Ana Lobo. Hoje em dia os Químicos têm software para o desenho de estruturas químicas, mas naquela altura eram feitas manualmente. A estrutura da penicilina, por exemplo, na capa do número 2 da série II, ao ser copiada pela gráfica ficou com as ligações um pouco "distorcidas”.

A Prof. a Ana Lobo foi a primeira Diretora do Boletim, tendo havido apenas três mulheres Diretoras neste período de 40 anos. Por coincidência, no período em que foi Diretora do Boletim a SPQ tinha como Presidente a Prof. ${ }^{a}$ Alzira Almoster Ferreira, que, curiosamente, foi também a primeira mulher a exercer este cargo na SPQ. Só em 2013 é que a SPQ viria a ter novamente uma mulher como Presidente, a Prof. ${ }^{a}$ Maria José Calhorda. Apesar da fraca projeção das mulheres em lugares de destaque naquela época, este facto não é visto como estranho. "Não! O Albertinho era um homem com uma mentalidade muito aberta”.

Numa chuvosa, e atípica, manhã de maio fui amavelmente recebido pelo Prof. Virgílio Meira Soares (Figura 3) na sua casa em Lisboa. Indicou-me a sala onde iríamos conversar e eu deslizei pelos tapetes de Arraiolos e afundei-me numa poltrona. A decoração da sala ajudou-me a recuar no tempo, mais precisamente a 1982.

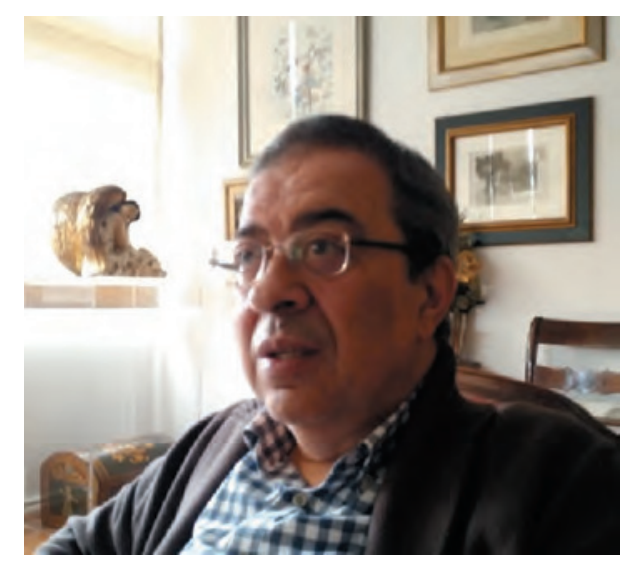

Figura 3 - Virgílio Meira Soares, Diretor do Boletim da SPQ de 1982 a 1984. 
O convite para integrar a Direção do Boletim da SPQ surgiu numa altura em o Prof. Meira Soares ainda estava a trabalhar no Complexo, pouco antes de ter ido para a Faculdade de Ciências da Universidade de Lisboa, e partiu do Prof. Romão Dias, na altura Secretário-geral da SPQ. No primeiro Editorial sob a sua Direção refere a difícil tarefa de suceder "a alguém [Prof. a Ana Lobo] que com a sua capacidade de trabalho o projetou para além dos limites da Sociedade [Portuguesa de Química].”

O Prof. Meira Soares manteve a linha editorial da Prof. ${ }^{a}$ Ana Lobo e, com a ajuda da equipa Editorial, o Boletim foi sendo construído com contribuições provenientes de convites e outras de cariz espontâneo. Na altura havia apoio de alguns laboratórios e a impressão era já feita com grande qualidade gráfica. Segundo o professor não se podia prever na altura que o Boletim viesse a assumir um papel tão relevante. Contudo, face à evolução que tem vindo a ocorrer ao nível da Educação, "não é de admirar o sucesso que teve”.

Naquela época as questões de Educação, nomeadamente no Ensino Superior, eram muito pouco valorizadas. Nesse sentido, o Boletim veio de certa forma colmatar essa falha e tornar-se uma ferramenta educativa e informativa, acessível a todos os Químicos. Em linha com a Direção anterior, onde se denota uma grande preocupação com o ensino da Química no Ensino Secundário [5,6], foram publicadas as comunicações apresentadas no "Bloco Ensino" do 4. ${ }^{\circ}$ Encontro Anual da SPQ [7]. Esta temática foi mais tarde, em 1991, novamente alvo de destaque [8]. Em 1993 (no número 48) foi criada a secção Ensino, a qual se passou a designar Química e Ensino (a partir do número 83) e que ainda subsiste.

A nomeação do Prof. Meira Soares para Secretário de Estado do Ensino Superior levou-o a deixar a Direção do Boletim, tendo feito apenas um mandato devido a incompatibilidade com as novas funções. Contudo, nas sua palavras "foi uma experiência muito enriquecedora ter colaborado, muito diretamente, com a Sociedade Portuguesa de Química”.

Bati à porta do gabinete do Prof. Berberan e Santos (Figura 4) no Complexo. Ele já estava à minha espera e convidou-me a entrar. O espaço do gabinete é reduzido, em parte devido à enorme e riquíssima coleção de livros e outra literatura científica que se acumula em seu redor.

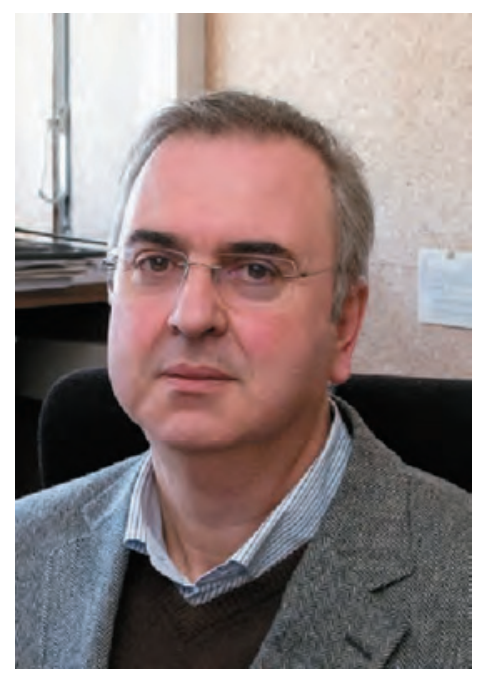

Figura 4 - Mário Nuno Berberan e Santos, Diretor do Boletim da SPQ de 1992 a 1994 e de 1997 a 1998.
O professor começou a colaborar no Boletim da SPQ em 1985, ainda como Editor Adjunto, vindo a tornar-se Diretor mais tarde (nos períodos 1992-1994 e 1997-1998). Naquela altura o Prof. Romão Dias era Secretário-geral da SPQ. Para além do trabalho editorial existiam mais tarefas! "Lembro-me de ir à tipografia, em Campolide, com o Moura Ramos [Diretor nesse período] ver provas.” A tipografia nem sempre tinha meios para fazer a distribuição dentro do prazo do envio a tarifa reduzida e "um dia carregámos nós próprios todos os Boletins para os Correios no carro dele, uma Dyane dois cavalos (risos)".

Quando assumiu a Direção do Boletim em 1992 tinha havido um interregno de cerca de um ano na sua publicação. “A SPQ passava por um período difícil, inclusive a nível financeiro, tendo sido revitalizada pelo José Artur [Martinho Simões], que era Secretário-geral. Foi ele quem me convidou para Diretor”. Ocorreu nesta altura uma total reestruturação do Boletim, com o objetivo de o tornar mais profissional. O Prof. Romão Dias, em fim de mandato como Presidente da SPQ, conhecia um jornalista do jornal Público, e convidou-o a trabalhar diretamente com o Prof. Berberan e Santos durante algum tempo de modo a atingir-se este objetivo. "O design gráfico ficou a cargo do Luís Moreira, que fez um excelente trabalho. O logótipo da SPQ também foi feito por ele”. Por diferentes motivos, as tipografias foram mudando ao longo do tempo. Na sequência desta reestruturação foram definidas as diferentes secções e os seus responsáveis. Para além das Notícias Gerais e das Notícias SPQ, criaram-se, entre outras, as novas secções Moléculas, Software, Técnicas Experimentais e Antologia (esta por iniciativa própria e para a qual o professor foi contribuindo), categorias que sobreviveram até ao número 80. A secção Ensino, tal como referido anteriormente, continua ativa. É de salientar a importância da secção Técnicas Experimentais, a qual continua ainda a ser uma referência de consulta por parte dos alunos.

"Foi sempre muito difícil conseguir a colaboração dos professores do Ensino Básico e Secundário. Por diversas razões. Os professores têm uma carga horária elevada, existe por vezes um isolamento dos professores nas suas Escolas e nem sempre os conteúdos do Boletim se articulam com as matérias lecionadas. Contudo, a secção Química e Ensino continua a ser muito importante.” Modificou-se também o nome do Boletim, tendo passado a chamar-se QUÍMICA. "Um nome simples e que definia perfeitamente a Revista”. "É curioso verificar que no número 68 (em 1998), o último número editado sob a minha Direção, o QUÍMICA contém um artigo sobre Dispositivos e Máquinas Moleculares, que resultou da tradução de uma palestra do Prof. Vincenzo Balzani. Um tema muito atual e que conduziu à atribuição do prémio Nobel da Química em 2016, embora ele não tenha sido contemplado. Este artigo, ainda hoje muito interessante, mostra que em Portugal se acompanhava a Ciência ao seu mais alto nível”.

A ideia de digitalizar as revistas da SPQ e colocá-las acessíveis a todos, incluindo o Boletim, foi uma iniciativa de extrema importância e partiu do Prof. Berberan e Santos. "Em 2004 iniciou-se a digitalização da Revista de Chimica Pura e Applicada, que era de difícil acesso, e cuja coleção na SPQ estava incompleta. Por outro lado, a coleção em papel contendo muitos exemplares de cada, e devido ao enorme 
peso, representava um perigo para a segurança do edifício.” No processo de digitalização conservou-se apenas um exemplar de cada número e completou-se a coleção com cópias dos números em falta usando a coleção particular do Prof. Berberan e Santos, única que se conhece com a encadernação original, comprada num alfarrabista em Faro. É curioso também o facto de, mais tarde, ter sido encontrada por acaso uma coleção desta revista num armário escondido do Laboratorio Chimico. Em junho de 2011, por ocasião do centenário da SPQ, foram colocadas online todas as revistas, num total de 24000 páginas. Este processo foi possível graças ao financiamento obtido através do projeto "Periódicos de Química Portugueses”, apoiado pela Fundação Calouste Gulbenkian.

Estes testemunhos, e os que se seguem, demonstram bem a importância que o Boletim da SPQ teve, e continua a ter, para a comunidade dos Químicos portugueses. É preciso não esquecer que só conhecendo o passado podemos verdadeiramente projetar o futuro.

\section{Referências}

[1] R. Gonçalves, Boletim da SPQ n. ${ }^{\circ} 39$ (1990) 59-64.

[2] Química n. ${ }^{\circ} 100$ (2006) 80-83.

[3] R. G. Carpentier, Boletim da SPQ, n. 7 (1981) 3-7.

[4] R.P.S. Fartaria, F. Pereira, V.D.B. Bonifácio, P. Mata, J. Airesde-Sousa, A.M. Lobo, Eur. J. Org. Chem. (2013) 1415-1419.

[5] A. Lopes, Boletim da SPQ n. 2 (Série I) (1977) 11.

[6] Boletim da SPQ n. ${ }^{\circ} 4$ (Série I) (1978).

[7] Boletim da SPQ n. ${ }^{\circ} 10$ (1982).

[8] Boletim da SPQ n. 49 (1991).

Entrevistas e texto de Vasco D. B. Bonifácio IST, Universidade de Lisboa

Tenho muito gosto em responder à solicitação que me foi feita para dar testemunho da minha experiência à frente do então «Boletim da SPQ». Muita coisa mudou entretanto. Houve pequenas mudanças formais na publicação, para além da melhoria notável da sua apresentação gráfica. Uma delas foi o título, que passou de «Boletim da SPQ» para «QUÍMICA». Outra foi o estatuto do responsável que passou de «Diretor» (que eu fui) para «Editor». Estas modificações podem não ser consensuais, mas não é isso que importa aqui.

O que mudou muito, desde a época em que fui Diretor do Boletim da SPQ até hoje, foi o ambiente reinante no sistema de ensino. A Universidade tinha admitido, no pós-25 de abril, um número elevado de novos docentes. Sabe-se hoje que isso introduziu mais tarde desequilíbrios e estrangulamentos, mas no período em que fui responsável pelo Boletim da SPQ, o corpo docente dos departamentos de Química era muito jovem. Como nessa altura ainda não reinavam a sina do «publish or perish» e o individualismo feroz daí resultante, podíamos contar com a disponibilidade e o entusiasmo de muita gente para colaborar, sem moeda de troca, em atividades paralelas à docência e à investigação.

No ensino secundário passavam-se coisas semelhantes, e o Boletim da SPQ, graças à sua primeira diretora, Ana Lobo, tornou-se um instrumento importante na ligação entre o ensino da Química no secundário e a Universidade.
Era assim quando me iniciei na tarefa de diretor do nosso Boletim, e assim foi ao longo do meu mandato. Os professores do secundário esperavam do Boletim apoio para a sua atividade docente, para a discussão das metodologias e conteúdos do seu ensino. A comunicação era viva e frequente.

O então Secretário-geral da SPQ, o saudoso amigo Alberto Romão Dias, via no Boletim uma dimensão importante da atividade da Sociedade, e não regateava apoio e solidariedade. Recordo também a colaboração de Químicos da indústria e do LNETI (Laboratório Nacional de Engenharia e Tecnologia Industrial, atualmente extinto) que proporcionou a publicação no Boletim de textos na fronteira entre a Química e as suas aplicações industriais. Bem como a de artistas plásticos e técnicos de conservação e restauro, que tornou possível a preparação de um número especial sobre «Química e Arte» que, pelos conteúdos e pela aparência estética, introduziu ar fresco na publicação.

Ter sido Diretor do Boletim da SPQ há cerca de 30 anos foi estimulante e compensador, o que naturalmente me deu muita satisfação e me deixou boas recordações.

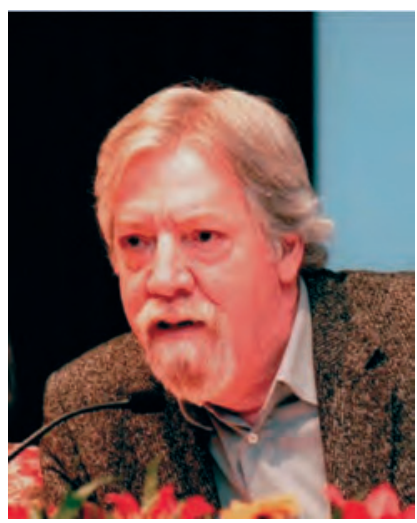

Joaquim Moura Ramos, Diretor do Boletim da SPQ de 1985 a 1988

Foi em dezembro de 1988 que o Boletim da SPQ n. ${ }^{\circ} 34$ (série II) veio a público. Uma nota editorial, ausente ainda de acordo ortográfico, assentava o curto texto em verbos e pronomes. Dizia assim:

\section{Nós}

O Boletim da Sociedade Portuguesa de Química tem-nos como novo grupo directivo. Tarefa difícil a nossa, a de tentar dirigí-lo com a qualidade imprimida pelo Joaquim Moura Ramos e seus adjuntos... Mas tentaremos, está prometido!

\section{Eles}

Grandes dinamizadores do Boletim são eles, os directores das secções temáticas. Contribuem, em directo com o saber da sua própria palavra e, em indirecto, com a mobilização da de outrem, no âmbito do tema que dirigem.

\section{Vós}

A Química é muito mais do que nós e eles! É, sobretudo, vós. E, sem vós, o Boletim não é. De vós, esperamos a vossa voz. O número três é um número mágico... tal como as três retortas da Sociedade Portuguesa de Química, se o quisermos... 
O novo grupo diretivo, por mim liderado, incluía os adjuntos Ana Simões (INIC), António Calado (FFUL), Lídia Albuquerque (FCUL) e Manuel Gil (EDP). Para além de "Informações, atualidade”, as secções temáticas estendiam-se por "Educação em Química”, “Química e Indústria”, “Evolução Química”, “Segurança nos Laboratórios”, ”Química e Saúde”, “Computadores em Química”, “História da Química” e “Congressos e Conferências”.

Foram mais de três anos de grande atividade, onde as reuniões da equipa nas decisões, distribuição de tarefas e construção de cada boletim ocuparam várias noites sem dormir. Sim, porque cada boletim era "fabricado" coluna a coluna, página a página, com as longas tiras de papel impresso que emergiam da gráfica. As figuras eram por nós colocadas, a publicidade também, um pouco de cola para tudo bater certo e, de novo, para a execução gráfica final. Sim, porque foram muitos os artigos que mereceram a nossa aturada atenção, e vários os que a nossa célere vontade permitiu a sua tradução em tempo útil. Cansaço, dever cumprido e contentamento em assalto permanente.

Desde o início que se assentou na feitura de um boletim temático anual, identificado com as nossas preocupações mais fundamentais, cujos artigos fossem elaborados por especialistas da área, a convite. Assim surgiu “A Química e o Ambiente” (n. ${ }^{\circ}$ 38), em dezembro de 1989, onde as contribuições dominantes vieram da universidade, dos organismos oficiais e das empresas, onde o ar, a água e o solo foram tema e onde a informação, a reflexão e a crítica fizeram pensar o homem. No dezembro seguinte “A Química e a Saúde” (n. ${ }^{\circ}$ 42) obrigou-nos a ponderar sobre a "qualidade de vida”, a segurança e o ambiente, a estreita relação da Química com a Farmacologia e a Medicina. “A Química e a Educação” (n. ${ }^{\circ} 46$; dezembro de 1991) foi incisiva na demonstração da influência do pensamento e ação do químico contemporâneo nos domínios individual e social do homem; e, como tal, ser tarefa do setor educativo apetrechar professores e alunos para essa realidade.

Nem internet, nem online; apenas bonitas capas (Figura 5) e manuseamento de papel.

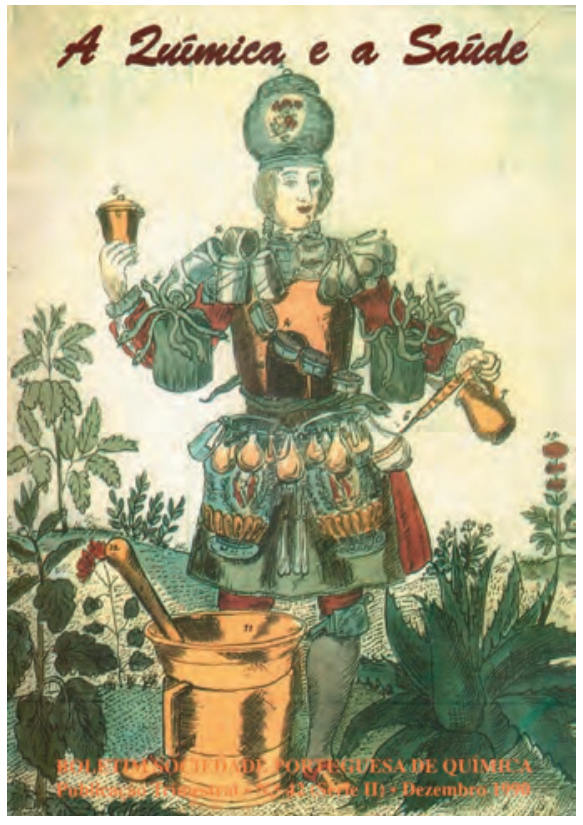

Figura 5 - Capa do Boletim da SPQ n. ${ }^{\circ} 42$ (1990).

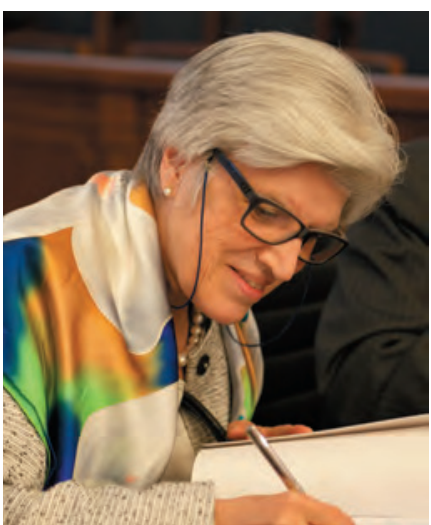

Raquel Gonçalves Maia Diretora do Boletim da SPQ de 1988 a 1991

Se bem me recordo fui Diretor do QUÍMICA de janeiro de 1995 (n. ${ }^{\circ}$ 56) a dezembro de 1996 (n. ${ }^{\circ}$ 63). Tinha eu 35 anos. Já lá vão cerca de 20 anos. De facto, o tempo dispara. Foram meus Adjuntos a Maria Helena Adão, o Hermínio Diogo, o Jorge Lampreia, a Benilde Saramago, e o Pedro Simões. Não posso deixar de referir a Cristina, a nossa única secretária, que fazia tudo (expediente, correspondência, contabilidade, tesouraria, organização dos Encontros, e ainda dar apoio ao QUÍMICA).

Foram tempos difíceis, com recursos muito escassos e a fazermos uma tiragem de 2200 exemplares. Mudámos completamente a estrutura, o design, e a capa do QUíMICA. Implementámos um novo sistema de inclusão de publicidade para fazer face aos custos.

A história mais engraçada - ou talvez não - de que me recordo, ocorreu precisamente no último número (n. ${ }^{\circ}$ 63). Por razões que não me lembro em pormenor, não pude coordenar efetivamente a fase final da publicação deste número do Boletim. Penso que estava numa visita a um laboratório fora. O highlight da revista (e tema da capa) foi sobre "Geometria e Estrutura”, de que destaco um excelente artigo, que recomendo a todos (re)lerem, da autoria do Jorge Calado. O título do artigo deveria ter sido "A Arquitectura das Moléculas: de Buckminster Fuller aos Fullerenos”. Acontece que, aquando da produção, em vez de Buckminster saiu Buckminister. O Jorge, rigorosíssimo em tudo o que faz e escreve, ficou furioso - e com razão. A diferença que um “i” pode fazer!

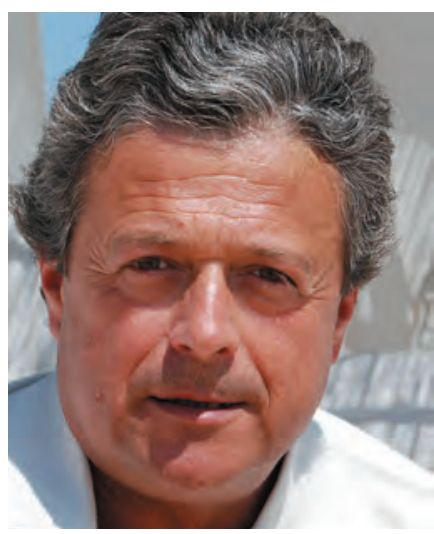

Luís Paulo N. Rebelo Diretor do Boletim da SPQ de 1995 a 1996 